\title{
Reframing the US Attendance Crisis: School Absences Send Powerful Signals about Children Nationally
}

\author{
Jaymes Pyne* \\ Stanford University \\ Eric Grodsky \\ University of Wisconsin-Madison
}

January 3, 2022

\begin{abstract}
Some believe that holding schools accountable for student attendance will lead schools to act to reduce student absences and by doing so will increase student achievement, particularly for historically underserved students. We question both the premise that reducing absence will lead to substantial improvements in student achievement and fairness of holding school accountable for increasing attendance. Using two cohorts of nationally-representative data on kindergarteners, we find that factors unrelated to missed instruction account for at least 77 percent of the association between attendance and test score achievement among US children with twenty or more absences. We argue the attendance crisis conceals more troubling crises that will produce inequalities even if every child attends school every day, and that schools are ill-suited to address all the underlying causes of student absence. Absence is a symptom of the myriad challenges students and their families face-challenges that need to be addressed at a larger systemic level.
\end{abstract}


With good reason, families are concerned that missing classroom instruction hurts children. Claims of an "attendance crisis" have resonated with educators and national policymakers alike for years (e.g., Harris, 2013; United States Departments of Education, 2015), due to its assumed impact on learning loss. Most prominently, in 2015, US Secretary of Education Arne Duncan, along with the Attorney General and others, warned that our nation must get "every student, every day to attend and be successful in school..." (p. 2), arguing that chronic absenteeism "is a primary cause of low academic achievement...." (p. v). Reflecting both policy concerns and research evidence, the 2015 Every Student Succeeds Act encourages states to hold schools accountable for student attendance, monitoring school performance in part based on the share of students missing 10 percent days or more of classroom instruction, the threshold for chronic absenteeism (Jordan \& Miller, 2017).

The notion that disparities in school attendance contribute appreciably to educational inequalities is compelling because the benefits of attending class seem so intuitive. Chronically absent children struggle academically (Gottfried \& Hutt, 2019). However, children who miss a lot of school would not necessarily enjoy outcomes like their peers were they to attend more frequently. Recent evidence from one Midwestern urban school district reinforces that assertion, estimating that noninstructional factors explain at least 88 percent of the association between 18 unexcused absences and children's achievement in the district (Pyne et al., 2021). Experimental studies provide evidence consistent with these results, suggesting successful efforts to get children to school and in class more often do not necessarily result in achievement gains (Heppen, Kurki, \& Brown, 2020; Tran \& Gershenson, 2021). This is because getting children to class does not address the litany of crises that undermine their learning whether they attend class or not.

In this paper, we broaden the scope of these studies by examining the attendance-achievement association among kindergarten-aged children nationally, across the US, in two cohorts of children attending kindergarten in 1998 and 2011. We 
do so to better understand the degree to which noninstructional factors explain associations between absence from school and academic achievement. Kindergartenaged children offer a compelling test of the "missed instruction" explanation of the attendance-achievement relationship; since kindergarteners are just beginning obligatory formal schooling, they have no prior years of missed instruction in elementary school. On the other hand, we can think of the variance in the association explained by noninstructional factors we observe as the "signal" school absences send about children's school and home lives that relate to both their attendance and achievement.

The two nationally-representative US datasets we use permit us to evaluate the relationship between learning over the course of the academic year (the difference in fall and spring scores on math and reading assessments), total days of school missed during the kindergarten school year, and a range of demographic, family, and healthrelated characteristics of children. In both cohorts, we find that the association between kindergarten absences and test score achievement in the US is mostly (but not entirely) spurious. For example, students who miss 20 or more days of kindergarten are expected to score a half a standard deviation less in math than children with no kindergarten absences. Noninstructional factors we observe explain 77 percent of that association, in both cohorts of children, leaving a gap of only 12$15 \%$ of a standard deviation unaccounted for. Results using reading test scores are largely the same.

These results are also consistent with work on the signal of school absences using detailed data from one Midwestern urban school district (Pyne et al., 2021) and with estimates reported in past quasi-experimental studies (i.e., Aucejo \& Romano, 2016; Carlsson, Dahl, Öckert, \& Rooth, 2015). As we discuss in closing, our study serves as not one, but two instances of nationally-representative evidence suggesting school attendance is mostly a signal of noninstructional aspects of children's lives that affect their academic achievement. The compelling and growing body of evidence this 
study bolsters calls into question the utility of sanctioning schools for the poor attendance of some of the students whom they serve and redirects attention to addressing the underlying causes rather than purported consequences of student absence.

\section{School Attendance and Academic Achievement}

For school to educate students, of course, students need to attend. Concerns about student attendance, often framed around chronic absence (missing 10\% or more of school days), have become prominent in discussions about school improvement, accountability, and achievement among students. Chronic absenteeism among schoolaged children has caught the attention of national policymakers, broadening the influence of school attendance as an important social policy topic. For example, in a 2015 joint letter, the US attorney general and the secretaries of Education, Housing and Urban Development, and Health and Human Services (2015, p. x) insist that "[a]s a nation, we must acknowledge that frequent absences from school can be devastating to a child's future." A year prior, Kamala Harris (then California's attorney general) alluded to a truancy crisis (McGreevy, 2014), and in 2013 released a study on truancy and absenteeism that stated emphatically, "[w]hen students miss school they are more likely to fall behind and eventually, to drop out" (Harris, 2013, p. 9). In response to national attention and legislative efforts such as the 2015 Every Student Succeeds Act, many states and school districts now adopt attendance policies that hold schools accountable for their students' absences (Jordan \& Miller, 2017). These policies, and the literature informing them, rely on the assumption that missing classroom instruction adversely affects the life-chances of the nation's children.

Many studies insist missing school limits later success_-and missing school frequently matters a lot (see Balfanz, 2016; Gottfried \& Hutt, 2019). The "attendance crisis" narrative has emerged in part from a long line of scholarship seeking to understand high school dropout. Early work focusing on the predictive power of school attendance finds qualities of first-grade students and their parents, 
communities, and schools predict earning a high school diploma many years later (Alexander, Entwisle, \& Horsey, 1997). In that study, first grade school absences are an early signal of dropout, but the authors assert that absences "probably reflect as much on conditions at home as on children's academic engagement" (p. 103).

Beyond missing instruction, however, attendance may also reflect underlying conditions that constrain children's attendance and limit their educational achievement. To some extent, these conditions vary by student age (Gottfried, 2009). While some adolescents may choose to skip school, children are more likely absent because of an illness, parental choice, socioeconomic disadvantage, or time and transportation constraints felt by their families (Gottfried \& Hutt, 2019). Healthrelated conditions and illnesses in particular can account for a significant proportion of missed school days (Akinbami, Moorman, \& Liu, 2011; Gee, 2019; Jackson, Vann, Kotch, Pahel, \& Lee, 2011; Torpy, Campbell, \& Glass, 2010). Although health complications can also lead to school absences, they often intersect with or are entirely endogenous to community environments that affect family finances, work schedules, and quality of home environment (Diette et al., 2000; Heissel, Persico, \& Simon, 2019; Hsu, Qin, Beavers, \& Mirabelli, 2016; Mizan, Shendell, \& Rhoads, 2011). Parents also influence whether children make it to class (Gee, 2019; Gottfried \& Hutt, 2019). Those who feel alienated from their child's school might be less concerned about school attendance (Chang \& Romero, 2008), while others lose track of how often their child is absent (Mac Iver \& Sheldon, 2019; Rogers \& Feller, 2018). Things like scheduling conflicts, car trouble, and family instability unintentionally disrupt regular school attendance as well (Gottfried, 2017; Hancock, Gottfried, \& Zubrick, 2018).

If school attendance affects student outcomes strictly through missed instruction, the reasons students miss school are less important, since students are missing valuable instructional time regardless of the reason. On the other hand, if different types of absence reflect different sets of underlying causes which themselves influence student learning, then associations between attendance and learning will vary 
across types of absence (Pyne et al., 2021). Absences result from family constraints and choices, the quality of parent-school relationships, or concerns about school climate as much as they may be due to health detriments of varying severity and duration. Differences in the association between type of absence and learning, therefore, suggest that it is not through missed instruction alone that absence matters. To the extent that absences simply reflect constraints on students and their families, reducing absences may be beyond the direct control of schools and may have relatively little bearing on student achievement or learning.

Beyond concerns about how attendance shapes average levels of student achievement, analysts and policymakers have been attentive to the ways in which attendance contributes to inequalities in achievement among students. Past research using nationally representative data (Gee, 2018; Jacob \& Lovett, 2017; Ready, 2010; Romero \& Lee, 2007) and state or district data (Ehrlich et al., 2013; Gershenson, Jacknowitz, \& Brannegan, 2017; Grigg, Connolly, D'Souza, \& Mitchell, 2015; Hough, 2019; Smerillo, Reynolds, Temple, \& Ou, 2018) demonstrate that Black students and those from less advantaged families have substantially higher absence rates, and are more likely to be chronically absent, compared to White students or students from more advantaged families. Whether or not increasing attendance is an equityenhancing strategy depends on the extent to which attendance influences achievement through exposure to instruction rather than due to confounders that shape both attendance and achievement.

\section{A Crisis of Missed Instruction or a Signal of Other Crises?}

We draw from logic presented by Pyne and colleagues (2021) to conduct a set of empirical tests that approximate the extent to which: (a) absence from school leads to variation in academic achievement and academic growth through missed instruction and (b) variation in attendance is associated with achievement due to confounders. If absences matter only due to missed instruction, then each one should have the same, 
or greater, unconditional associations with achievement. The missed instruction hypothesis implies that we will see uniform learning gaps for each additional absence or wider gaps as the number of absences increases and students lack the prior knowledge necessary to make sense of new content. In contrast, if absences primarily reflect confounders rather than missed instructional time, then the first absence may appear most impactful because it distinguishes between students who are either ever or never absent. While additional absences may be associated with further decrements to achievement, the initial absence should appear most consequential.

Hypothesis 1: The unconditional association between each additional absence and achievement is constant or increasing across absences.

Second, disadvantaged children not only miss more school, but also may learn less when they are in school for any number of reasons. Conditioning on a variety of factors may show that the observed associations between school attendance and academic achievement is confounded. We can estimate academic growth over time by observing changes in students' test scores from fall to spring in the same academic year. Then, we condition our estimates on a range of health conditions which may contribute to attendance and learning. If absences operate on achievement through missed instruction, then we should observe little change in the association between absence and instruction net of other potential confounders. Alternatively, if confounders drive the association between attendance and achievement, then conditioning on confounders should substantially attenuate the relationship between attendance and achievement.

Hypothesis 2: Conditioning on observable differences among students will do little if anything to attenuate the relationship between school attendance and academic achievement.

\section{Data and Analysis}

\section{Sample}


Our data come from the kindergarten years of the Early Childhood Longitudinal Study: 1998 Kindergarten cohort (ECLS-K:1998) and the 2011 Kindergarten cohort (ECLS-K:2011). Both panel studies include nationallyrepresentative samples of schools and children as they enter elementary school. We account for missing data using multiple imputation by chained equations over five imputed data sets, with ECLS-K survey weights applied. The ECLS-K:1998 imputed sample includes 18,456 student observations and the ECLS-K:2011 imputed sample includes 17,143 student observations with information on fall and spring reading and math cognitive assessments. We focus our study on reading and math test score achievement when children both begin and end kindergarten-as children first enter elementary school —which mitigates worry that accounting for prior achievement influences past missed instruction.

\section{Measures}

We evaluate children's performance on assessments of verbal and mathematical skill in both ECLS-K cohorts, with responses to items scaled based on a three-parameter IRT model. We standardize both fall and spring scores and include fall scores in models of spring achievement. Our main independent variable of interest captures teachers' reports of each child's absences over their kindergarten school year. This measure differentiates among children with zero, one to four, five to seven, eight to ten, eleven to nineteen and twenty or more absences in kindergarten. Weighted descriptive statistics imply that nationally, roughly four percent of kindergartners have no absences, 83 percent have between one and ten absences, 10 percent have between eleven and nineteen absences, and three percent have 20 or more absences.

We also consider a range of demographic, health-related, social-emotional and family characteristics of children that may contribute to spurious associations between school attendance and missed classroom instruction. Demographic characteristics include each child's gender, race or ethnicity, family income, and parents' highest level of education. We also consider a range of health, behavioral and social-emotional 
indicators reported by both parents and teachers in the fall of kindergarten. These include child's overall health, BMI based on parent-reported weight and height of the child, birthweight, their incoming proclivity to malinger, and reports of their incoming social and behavioral skills (i.e., internalizing and externalizing behaviors, approaches to learning, interpersonal behavioral skills, self-control). The ECLS-K:2011 allows us to measure children's incoming executive functioning skills, but the ECLS-K:1998 does not. There are also several qualities of parents we account for in both cohorts, including the degree to which parents engage in home-based and school-based educational practices at the start of kindergarten, which may partially account for how parental relationships and engagement in their child's school can affect both school attendance and learning.

\section{Analytic Strategy}

We first examine unconditional associations between absences and test score achievement among kindergartners in each cohort. Next, we condition on prior fall test scores and a range of demographic, social-emotional, family, and health-related indicators at kindergarten entry. We compare these estimates to those from previous work using both quasi-experimental designs and correlational designs much like ours. In particular, we draw on estimates reported by Pyne and colleagues (2021), who examine the association between total absences and math or reading test scores in a Midwestern urban school district. Although that paper focused mainly on type of absence (i.e., excused or unexcused) and test score achievement, we use estimates from models on total absences (i.e., rounded and reported in columns 1, 3, 4, and 6 in Table S2 found in their online supplement) to construct corresponding comparison figures.

Finally, we build on the results of fully saturated models to estimate the differences in expected outcomes, between model estimates and counterfactuals in which no child has any absences in kindergarten. All models account for missing data using multiple imputation by chained equations, with survey weights applied. The 
public-use versions we use of the ECLS-K:1998 and ECLS-K:2011 can be found at https://nces.ed.gov/ecls/dataproducts.asp.

\section{Results}

We find that school absences have strong but spurious associations with test scores among both cohorts of our nation's kindergartners. Figure 1, Panel A, displays ECLS-K:2011 estimates of the association between math test scores and frequency of school absences. The first set of estimates in black are associations between number of absences and test score achievement among US kindergartners, relative to scores of peers with no absences. These associations reflect what educators may perceive as consequences of missing instruction. Children with one to four absences have spring reading test scores that are comparable to their peers with perfect attendance, while children with 20 or more absences_-about three percent of 2011 US kindergartnershave reading test scores two-thirds of a standard deviation lower than a child with no absences.

The second set of estimates in light grey represent math achievement in the spring of kindergarten, conditional on prior fall achievement and a set of demographic, health and family characteristics measured at kindergarten entry. We find that absence from school is conditionally unrelated to math test scores in kindergarten for those with fewer than 20 absences. Considering both conditional and unconditional estimates, factors other than missing instruction in kindergarten explain at least 78 percent of the association between 20 or more absences and math achievement (i.e., 0.15/-0.67 = 0.78). Figure 1, Panel B shows ECLS-K:1998 estimates of the association between math test scores and frequency of school absences, which follow nearly identical patterns, including the proportion of the association between 20 or more absences and math achievement explained by noninstructional factors (i.e., - $0.12 /-0.51$ $=0.76)$. Figure 1, Panel C shows estimates of associations between total absences and math test score achievement derived from supplemental materials in Pyne and 
colleagues (2021). Again, the estimates are quite similar to those in the two nationallyrepresentative cohorts, including the amount of variance in the association between 20 absences and math test score achievement explained by noninstructional factors (i.e., $-0.17 /-0.59=0.71)$

Figure 2 displays the same trends in kindergarten reading test score achievement, by frequency of school absences. In Panel A, reporting ECLS-K:2011 reading test score results, achievement estimates in black suggest that the average child with 20 or more absences can expect to have a spring math test score over half of a standard deviation lower than a typical child with no absences. Accounting for fall scores and additional confounders explains 79 percent of that association. Figure 2, Panel B reports ECLS-K:1998 reading test score results, which are functionally similar to the 2011 cohort results. However, variance explained by noninstructional factors is considerably lower by comparison, accounting for 65 percent of the association between reading test scores and 20 absences among 1998 kindergarteners. Figure 2, Panel C shows trends derived from estimates of third grade reading test score achievement reported by Pyne and colleagues (2021). These estimates are quite different from the national samples among children with many absences; conditional growth estimates suggests no amount of absences should have much of an impact on third grade reading test score growth, net of controls. Finally, Figure 3 shows that estimates of the association between 20 or more absences and math test score growth from both ECLS-K cohorts are similar to estimates calculated from previous studies.

In 2015, the US attorney general and the secretaries of Education, Housing and Urban Development, and Health and Human Services released a joint open letter to promote the "Every Student, Every Day" toolkit for preventing chronic absenteeism. The implicit messaging throughout the letter and attached report is that schools should work to get all students as close to perfect attendance as possible if the nation is to solve the attendance crisis. Figure 4 estimates the impact of such a herculean feat, displaying differences between predicted and counterfactual 
distributions of conditional reading and math test score achievement for both ECLSK cohorts of children. The reference distribution (the solid line) on each graph is the national distribution of predicted scores from "Growth + Controls" models in Figures 1 and 2. The counterfactual distribution (the dashed line) is the national distribution of predicted scores when every child has no absences and other covariates are left unchanged. Results suggest that kindergarten reading and math test score distributions would barely change if all children in the nation attended school every day.

\section{Discussion}

Results from two nationally-representative cohorts of US kindergarteners suggest that, at most, 23 percent of the relationship between school absences and test score achievement is due to missed instruction. That proportion equates to between $0.13-0.16$ standard deviation decrements in test score growth over the kindergarten year for children missing 20 or more days of school, compared to peers missing no school. That means at least 77 percent of the relationship between attendance and achievement during kindergarten is due to factors beyond missed instruction-many of which occur outside of schools. Counterfactual estimates derived from our models suggest perfect attendance among all kindergartners in the US would do little to change the distribution of reading or math test scores nationally. Considering these findings among two independent, nationally-representative cohorts of children-and quite similar findings from a single large urban school district (Pyne et al., 2021), we anticipate anyone with access to the same data elements on children's attendance, lagged test score achievement, and demographic information will find much the same.

We conclude that absences mostly signal challenges children and families face unrelated to the content of missed instruction. Prominent researchers, politicians and bureaucrats have decried an attendance crisis in our nation's schools, resulting in federal and state accountability policies that incentivize schools to simply get children to show up to class. We understand the appeal of this strategy to practitioners; 
typically, educators and advocates do not make statistical adjustments when assessing children's needs. They may consequently ascribe poor performance in class to missed instruction, rather than to many other social, economic, and health-related factors that continue to adversely impact children even when they attend school. The attendance crisis narrative suggests that getting every child to school every day would go a long way toward educational equality (see "Every Student, Every Day", 2015). We find that unlikely.

However, we agree missing very large amounts of instruction inhibits learning, particularly for less advantaged students. There is not yet definitive evidence on learning loss incurred by the COVID-19 pandemic, although some analysts are offering estimates based on learning loss resulting from school absences (Kuhfeld et al., 2020). We worry that estimates based on school attendance literature may be misleading, since we show how past claims about the detrimental effects of missing school, for even as much as a month, are likely overstated. Comparing associations of observed attendance rates with learning imply that if there was an attendance crisis prior to the pandemic, that crisis had far less bearing on academic growth than the underlying stresses endured by children and their families that contribute to poor attendance. During the pandemic, those inequities, and many more, spread through our communities and have grown more troubling by the day.

As Gottfried and Kirsky (2017) have pointed out, "[p]olicy and practice have charged forward with emphasizing the necessity to reduce school absenteeism" ( $p$. 119). That rush to find solutions for chronic absenteeism may have resulted in an overreliance on higher school attendance rates to correct a great many social ills it surely cannot. Part of the allure of an "attendance crisis" narrative is that Americans hold great expectations for our education system as both an economic driver and a means of legitimating economic inequalities later in life. These expectations, referred to by Grubb and Lazerson (2005, p. 315) as part of the "Education Gospel," require 
"improvements in education rather than parallel changes in workplaces or other social and economic policies necessary to achieve equality of opportunity."

Such expectations often fall short. Instead, policymakers should attend more to aspects of children's lives beyond the school's walls to achieve equity and expand opportunities for all. We urge researchers and policymakers to acknowledge that absence from school signals many challenges in children's lives, in addition to missing in-school learning opportunities. Seeing excessive absences as a warning signal motivates work addressing the out-of-school challenges children face that affect both attendance and academic achievement. Responding to the signal of school absence requires our nation's schools, and many more institutions, to provide broader support for our nation's children so they enjoy greater equity, opportunity, and social mobility in our society. 


\section{References}

Akinbami, L. J., Moorman, J. E., \& Liu, X. (2011). Asthma prevalence, health care use, and mortality: United States, 2005-2009 National Health Statistics Report. Washington, DC: US Department of Health and Human Services.

Alexander, K. L., Entwisle, D. R., \& Horsey, C. S. (1997). From first grade forward: Early foundations of high school dropout. Sociology of Education, 70(2), 87-107.

Aucejo, E. M., \& Romano, T. F. (2016). Assessing the effect of school days and absences on test score performance. Economics of Education Review, 55, 70-87.

Balfanz, R. (2016). Missing school matters. Phi Delta Kappan, 98(2), 8-13.

Carlsson, M., Dahl, G. B., Öckert, B., \& Rooth, D.-O. (2015). The effect of schooling on cognitive skills. Review of Economics and Statistics, 97(3), 533-547.

Chang, H. N., \& Romero, M. (2008). Present, engaged, and accounted for: The critical importance of addressing chronic absence in the early grades. Report. New York: National Center for Children in Poverty.

Diette, G. B., Markson, L., Skinner, E. A., Nguyen, T. T. H., Algatt-Bergstrom, P., \& Wu, A. W. (2000). Nocturnal asthma in children affects school attendance, school performance, and parents' work attendance. Archives of Pediatrics \& Adolescent Medicine, 154(9), 923-928.

Ehrlich, S. B., Gwynne, J. A., Pareja, A. S., Allensworth, E. M., Moore, P., Jagesic, S., \& Sorice, E. (2013). Preschool attendance in Chicago Public Schools:

Relationships with learning outcomes and reasons for absences. Chicago, IL: University of Chicago Consortium on Chicago School Research.

Every Student Succeeds Act of 2015, pub. L., 114 C.F.R. (2015).

Gee, K. A. (2018). Minding the gaps in absenteeism: Disparities in absenteeism by race/ethnicity, poverty and disability. Journal of Education for Students Placed at Risk (JESPAR), 23(1-2), 204-208.

Gee, K. A. (2019). Variation in chronic absenteeism: The role of children, classrooms, and school. In M. A. Gottfried \& E. L. Hutt (Eds.), Absent from school: Understanding and addressing student absenteeism (pp. 35-51). Cambridge, MA: Harvard Education Press.

Gershenson, S., Jacknowitz, A., \& Brannegan, A. (2017). Are student absences worth the worry in US primary schools? Education Finance and Policy, 12(2), 137-165.

Gottfried, M. A. (2009). Excused versus unexcused: How student absences in elementary school affect academic achievement. Educational Evaluation and Policy Analysis, 31(4), 392-415.

Gottfried, M. A. (2017). Linking getting to school with going to school. Educational Evaluation and Policy Analysis, 39(4), 571-592.

Gottfried, M. A., \& Hutt, E. L. (2019). Introduction. In M. A. Gottfried \& E. L. Hutt (Eds.), Absent from school: Understanding and addressing student absenteeism (pp. 1-14). Cambridge, MA: Harvard Education Press. 
Gottfried, M. A., \& Kirksey, J. J. (2017). “When” students miss school: The role of timing of absenteeism on students' test performance. Educational Researcher, 46(3), 119-130.

Grigg, J., Connolly, F., D'Souza, S., \& Mitchell, C. (2015). Kindergarten attendance and readiness for Baltimore's class of 2027. Baltimore, MD: Baltimore Education Research Consortium.

Grubb, W. N., \& Lazerson, M. (2005). The education gospel and the role of vocationalism in American education. American Journal of Education, 111(3), 297-319.

Hancock, K. J., Gottfried, M. A., \& Zubrick, S. R. (2018). Does the reason matter? How student-reported reasons for school absence contribute to differences in achievement outcomes among 14-15 year olds. British Educational Research Journal, 44(1), 141-174.

Harris, K. (2013). In school and on track: Attorney Heneral's 2013 report on Califonia's elementary school truancy \& absenteeism crisis. Sacramento, CA: California Department of Justice.

Heissel, J., Persico, C., \& Simon, D. (2019). Does pollution drive achievement? The effect of traffic pollution on academic performance. National Bureau of Economic Reserach Working Paper Series No. 25489.

Heppen, J. B., Kurki, A., \& Brown, S. (2020). Can texting parents improve attendance in elementary school? A test of an adaptive messaging strategy. Washington, DC: Institute of Education Sciences.

Hough, H. (2019). Roll call. In M. A. Gottfried \& E. L. Hutt (Eds.), Absent from school: Understanding and addressing student absenteeism (pp. 15-33). Cambridge, MA: Harvard Education Press.

Hsu, J., Qin, X., Beavers, S. F., \& Mirabelli, M. C. (2016). Asthma-related school absenteeism, morbidity, and modifiable factors. American Journal of Preventive Medicine, 51(1), 23-32.

Jackson, S. L., Vann, W. F., Kotch, J. B., Pahel, B. T., \& Lee, J. Y. (2011). Impact of poor oral health on children's school attendance and performance. American Journal of Public Health, 101(10), 1900-1906.

Jacob, B. A., \& Lovett, K. (2017). Chronic absenteeism: An old problem in search of new answers. Washington, DC: Brookings Institution.

Jordan, P. W., \& Miller, R. (2017). Who's in: Chronic absenteeism under the Every Student Succeeds Act. Washington, D.C.: FutureEd.

Kuhfeld, M., Soland, J., Tarasawa, B., Johnson, A., Ruzek, E., \& Liu, J. (2020). Projecting the potential impacts of COVID-19 school closures on academic achievement. Providence, RI: Annenberg EdWorking Paper SEries.

Mac Iver, M. A., \& Sheldon, S. b. (2019). Keeping families front and center: Leveraging our best ally for ninth-grade attendance. In M. A. Gottfried \& E. L. Hutt (Eds.), Absent from school: Understanding and addressing student absenteeism (pp. 181-198). Cambridge, MA: Harvard Education Press. 
McGreevy, P. (2014, March 10). Atty. Gen. Kamala Harris proposes new antitruancy laws for California. The Los Angeles Times. Retrieved from https://www.latimes.com/local/political/la-me-pc-attorney-general-harrissponsors-antitruancy-bill-package-20140310-story.html

Mizan, S. S., Shendell, D. G., \& Rhoads, G. G. (2011). Absence, extended absence, and repeat tardiness related to asthma status among elementary school children. Journal of Asthma, 48(3), 228-234.

Pyne, J., Grodsky, E., Vaade, E., McCready, B., Camburn, E., \& Bradley, D. (2021). The signaling power of unexcused absence from school. Educational Policy.

Ready, D. D. (2010). Socioeconomic disadvantage, school attendance, and early cognitive development: The differential effects of school exposure. Sociology of Education, 83(4), 271-286. doi:10.1177/0038040710383520

Rogers, T., \& Feller, A. (2018). Reducing student absences at scale by targeting parents' misbeliefs. Nature Human Behaviour, 2, 335-342.

Romero, M., \& Lee, Y.-S. (2007). A national portrait of chronic absenteeism in the early grades. Retrieved from New York: http://www.nccp.org/publications/pdf/text_771.pdf

Smerillo, N. E., Reynolds, A. J., Temple, J. A., \& Ou, S.-R. (2018). Chronic absence, eighth-grade achievement, and high school attainment in the Chicago Longitudinal Study. Journal of School Psychology, 67, 163-178.

Torpy, J. M., Campbell, A., \& Glass, R. M. (2010). Chronic diseases of children. $J A M A, 303(7), 682-682$.

Tran, L., \& Gershenson, S. (2021). Experimental estimates of the student attendance production function. Educational Evaluation and Policy Analysis. doi:10.3102/0162373720984463

United States Departments of Education, H. a. H. S., Housing and Urban Development, and Justice. (2015). Every student, every day: A community toolkit to address and eliminate chronic absenteeism. Washington, D.C. 


\section{Figures}

Figure 1. School Absences and Math Test Score Achievement

\section{Panel A. ECLS-K:2011 Cohort (Kindergarten)}

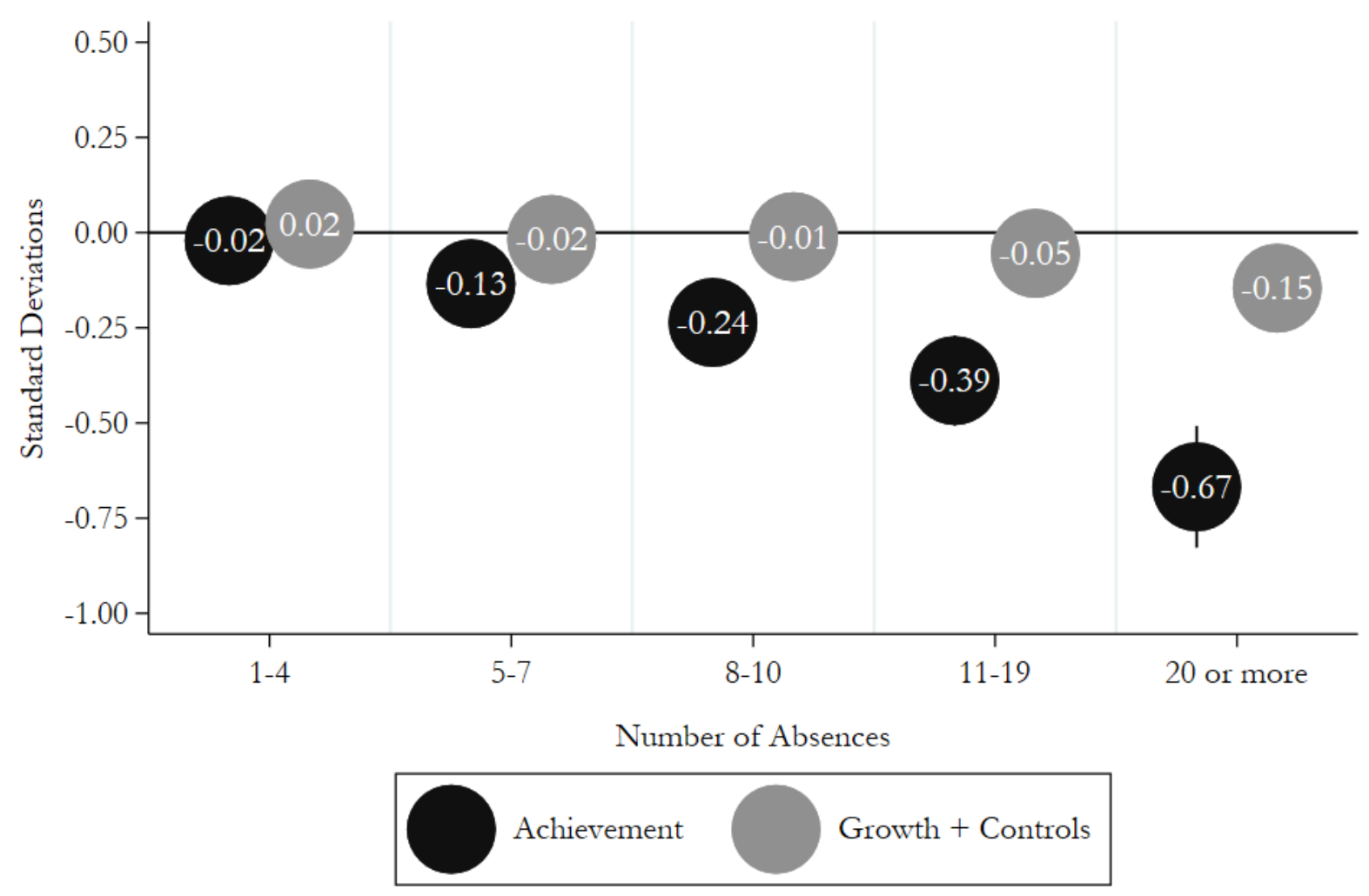


Panel B. ECLS-K:1998 Cohort (Kindergarten)

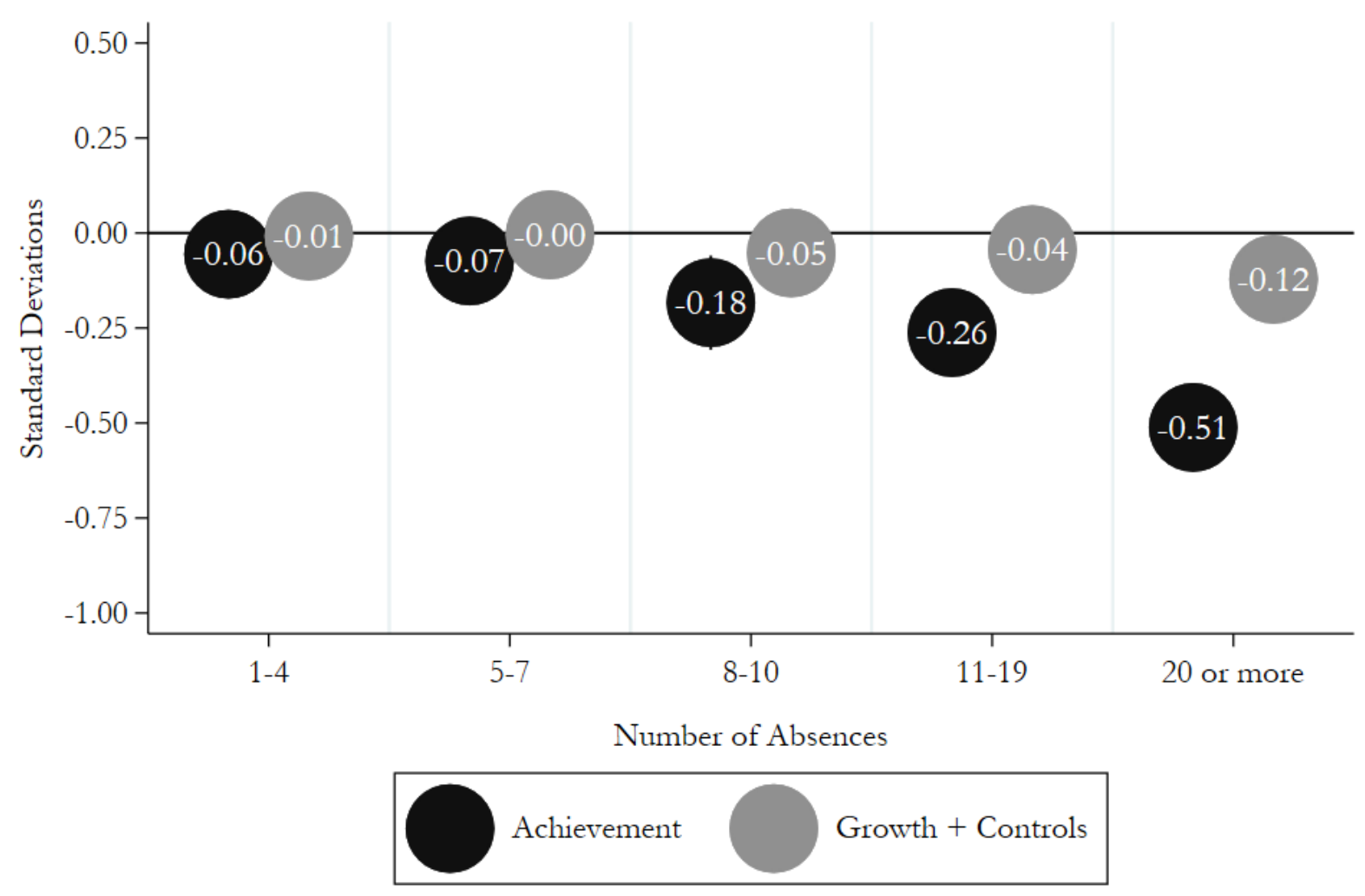


Panel C. Madison Metropolitan School District ( $3^{\text {rd }}$ Grade; Pyne et al., 2021)

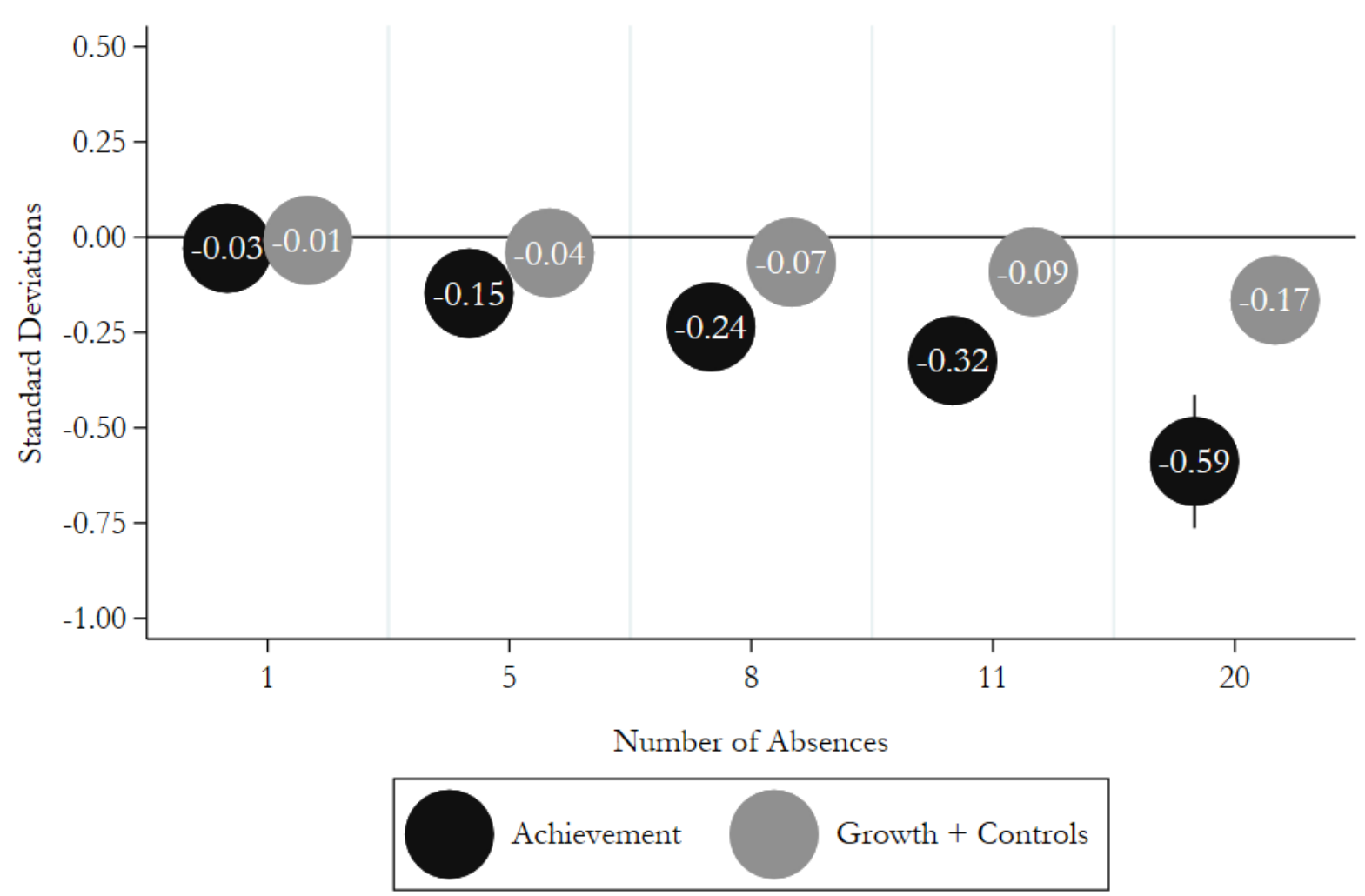

Sources: ECLS-K:2011 (N=17,143); ECLS-K:1998 (N=18,456); Madison Metropolitan School District (N=11,001). Note: Each sample includes children with full information on spring math cognitive assessments. The dependent variable is standardized math score from the spring cognitive assessment. Absences are teacher-reported absences for each child for the school year. Model 1 is the association between a child's frequency of absence from school and their test score achievement. Model 2 accounts for fall test score achievement and a range of demographic, family, and health-related characteristics of children at kindergarten entry. ECLS-K 1998 and 2011 cohort models account for missing data using multiple imputation by chained equations over five imputed data sets, with survey weights applied. Madison Metropolitan School District figure was created using estimates reported in Pyne et al. (2021). 
Figure 2. School Absences and Reading Test Score Achievement

Panel A. ECLS-K:2011 Cohort (Kindergarten)

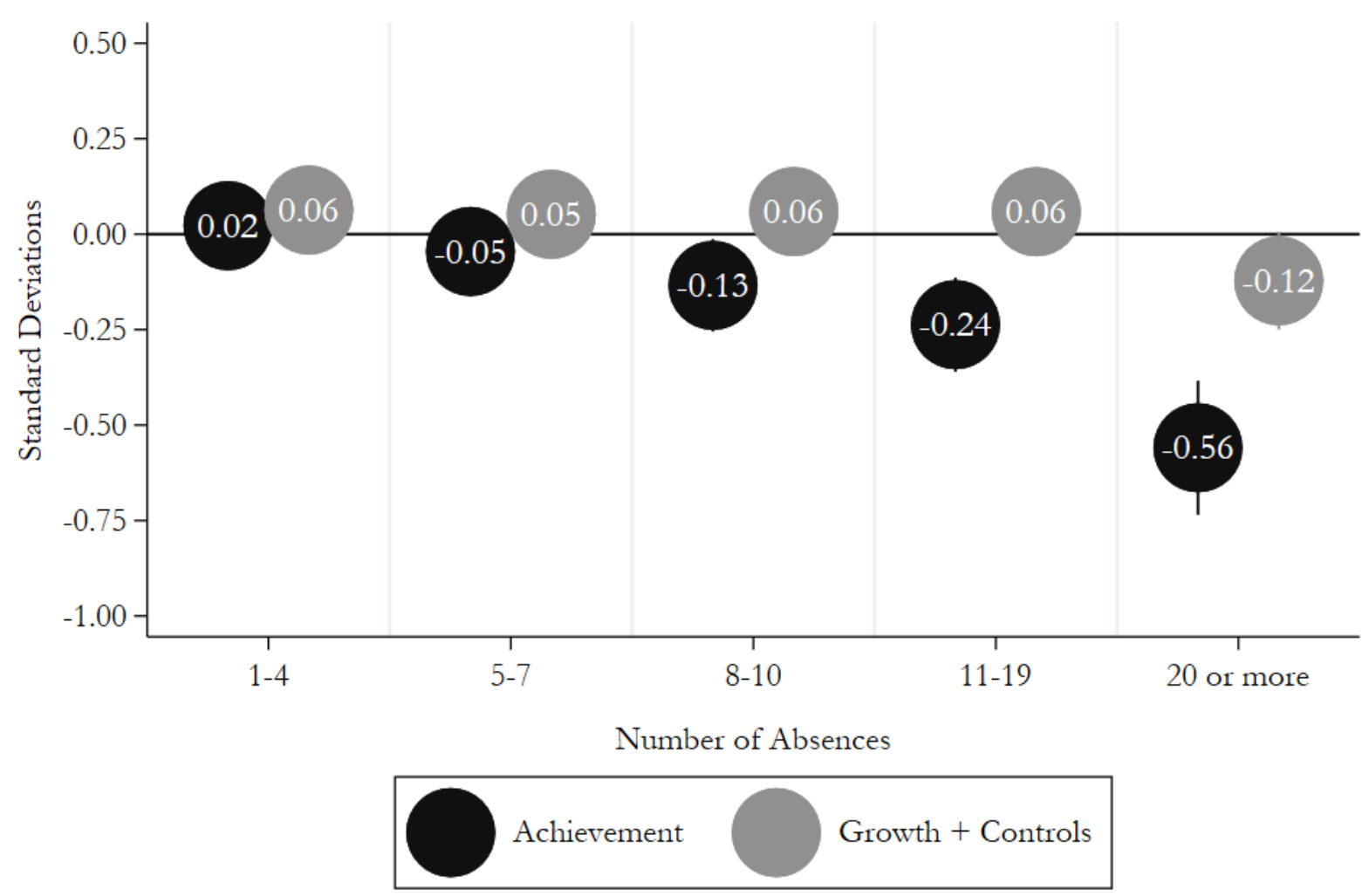


Panel B. ECLS-K:1998 Cohort (Kindergarten)

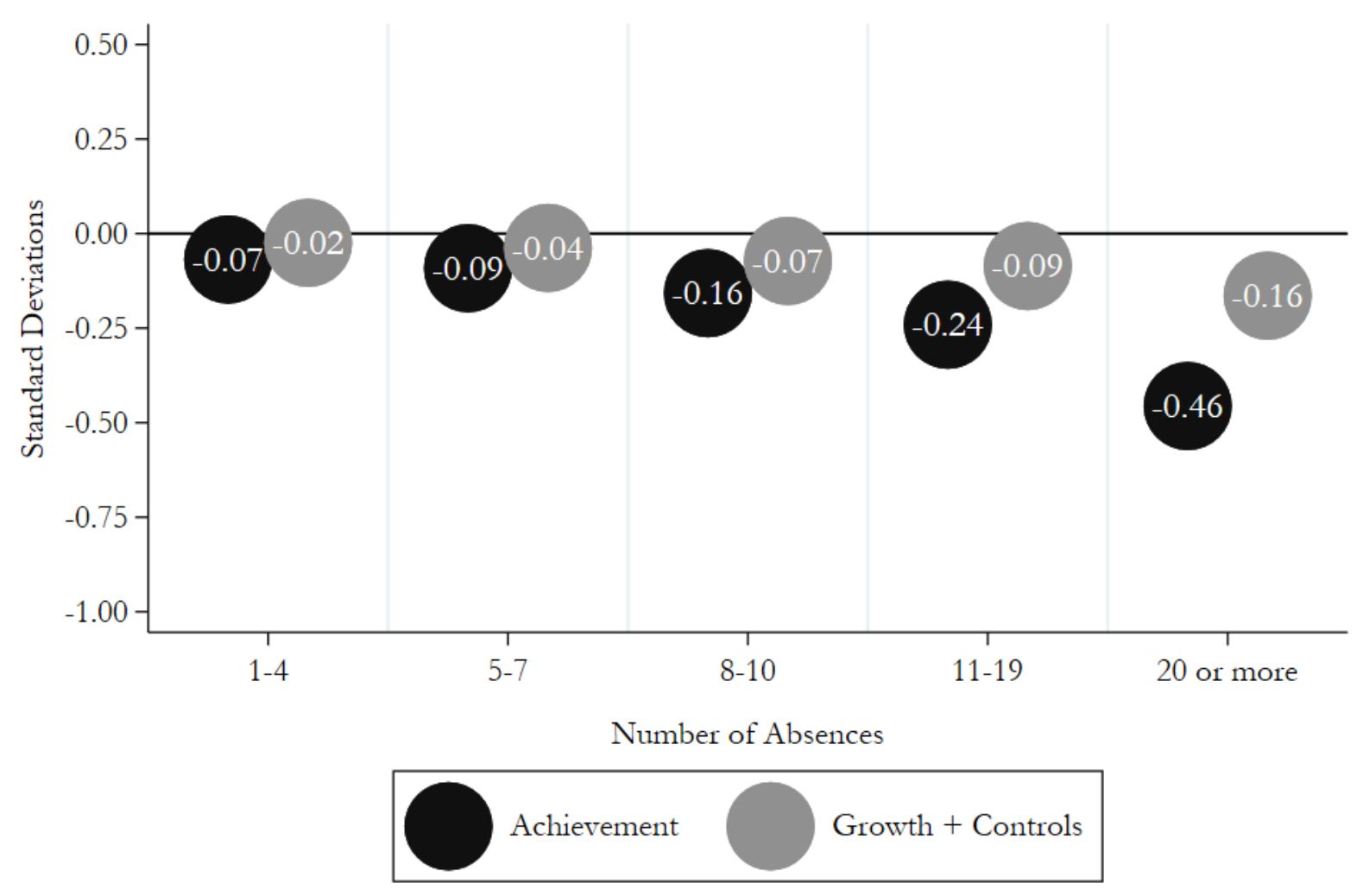


Panel C. Madison Metropolitan School District ( $3^{\text {rd }}$ Grade; Pyne et al., 2021)

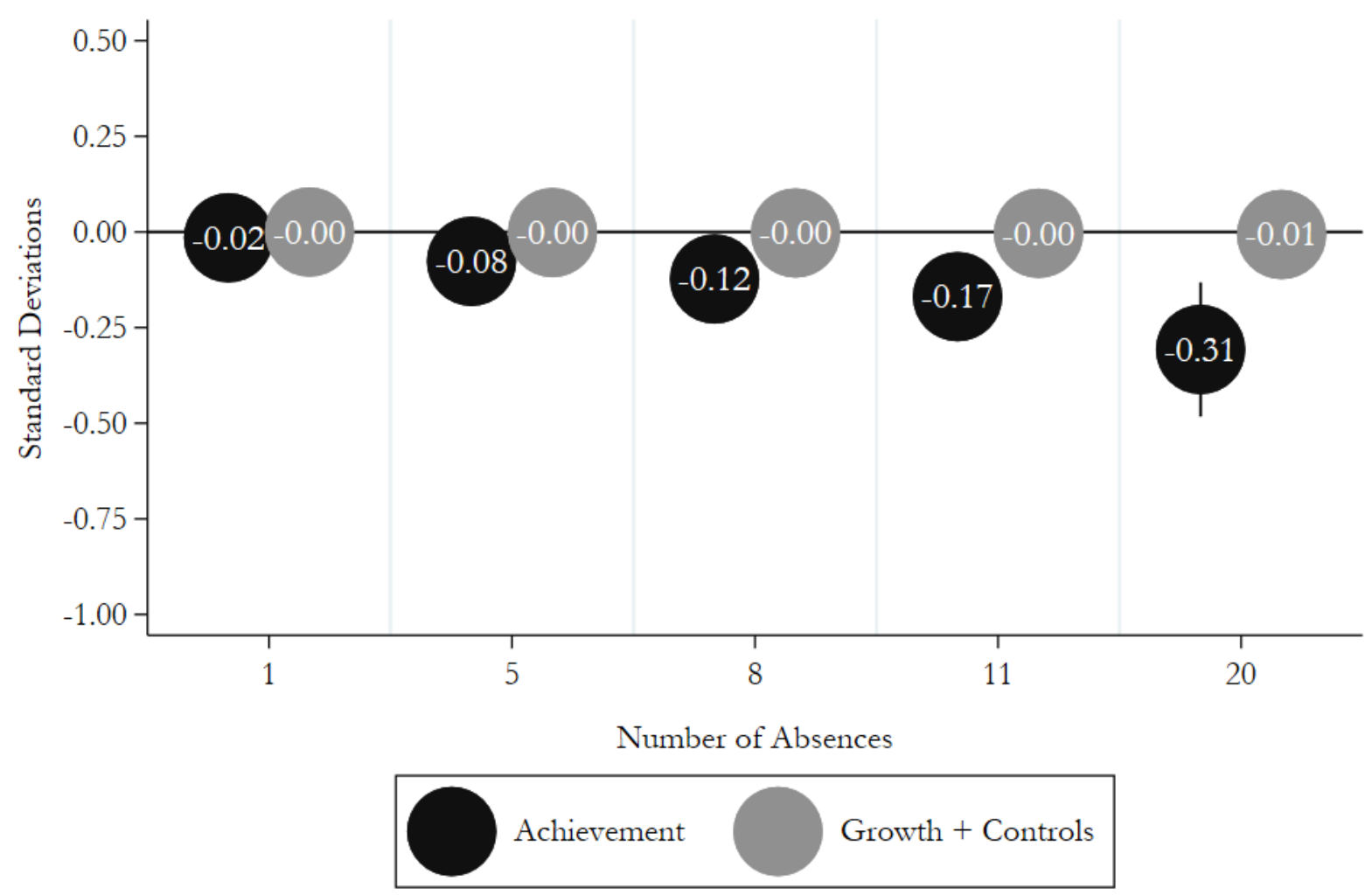

Sources: ECLS-K:2011 (N=17,143); ECLS-K:1998 (N=18,456); Madison Metropolitan School District (N=11,001). Note: Each sample includes children with full information on spring reading cognitive assessments. The dependent variable is standardized reading score from the spring cognitive assessment. Absences are teacher-reported absences for each child for the school year. Model 1 is the association between a child's frequency of absence from school and their test score achievement. Model 2 accounts for fall test score achievement and a range of demographic, family, and healthrelated characteristics of children at kindergarten entry. ECLS-K 1998 and 2011 cohort models account for missing data using multiple imputation by chained equations over five imputed data sets, with survey weights applied. Madison Metropolitan School District figure was created using estimates reported in Pyne et al. (2021). 
Figure 3. Reported Associations between 20 or More Absences and Math Test Score Growth

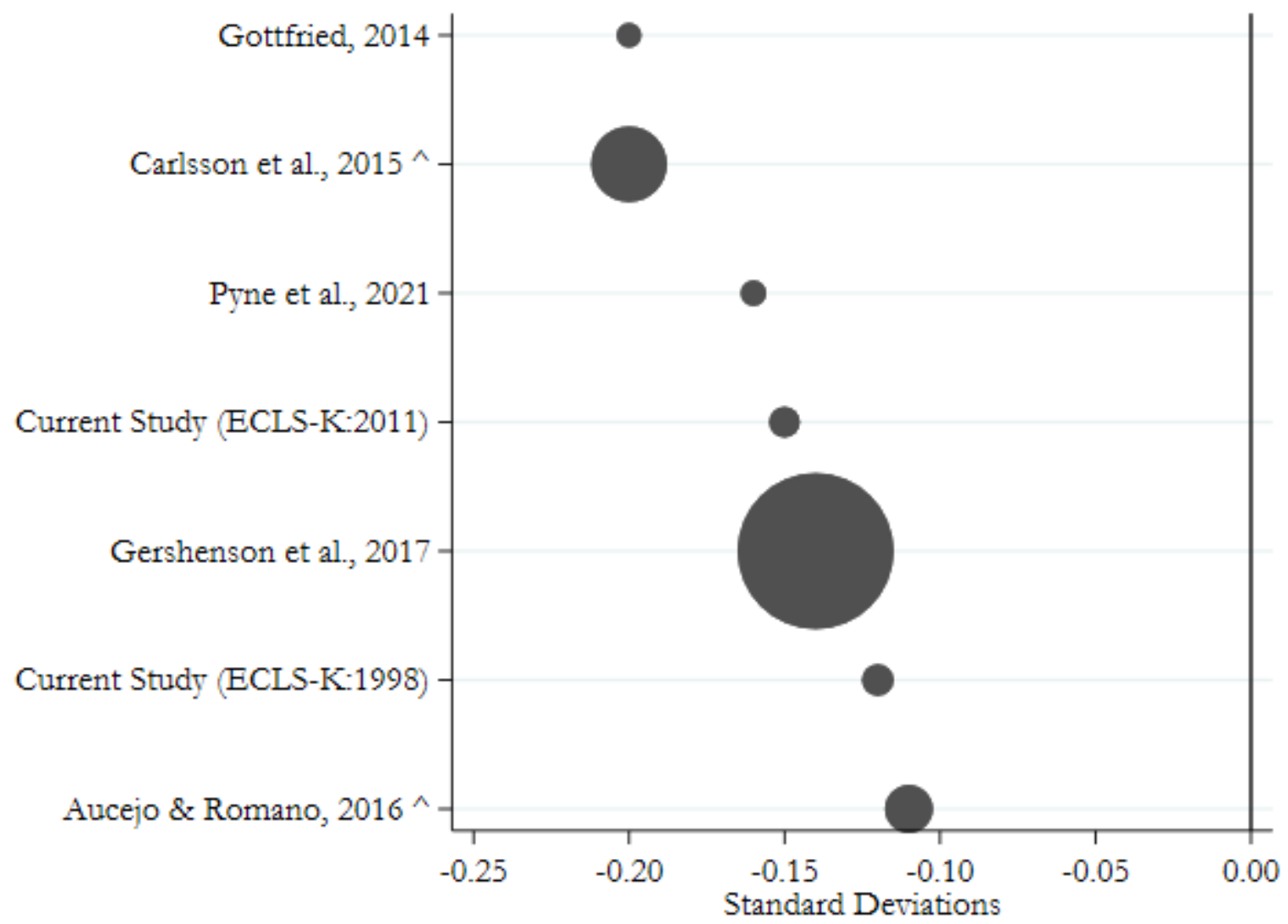

Notes: ${ }^{\wedge}$ denotes a quasi-experimental design. 
Figure 4. National Distributions of Kindergarten Test Scores Based on Observed and Counterfactual Frequencies of Absences.

Panel A. ECLS-K:2011 Cohort Reading Test Score Distribution

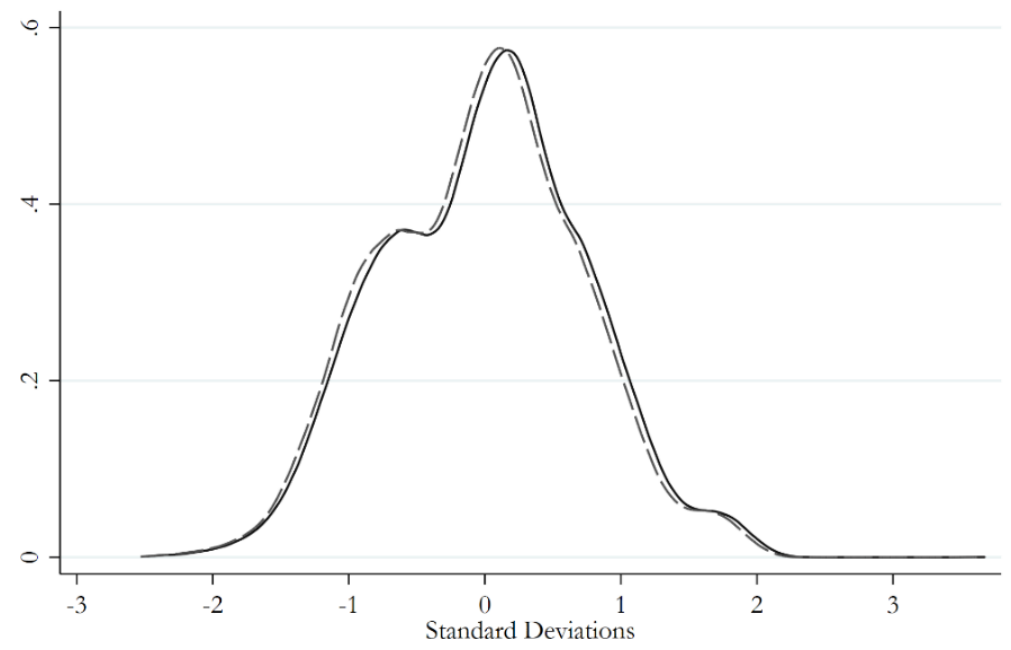

Panel B. ECLS-K:1998 Cohort Reading Test Score Distribution

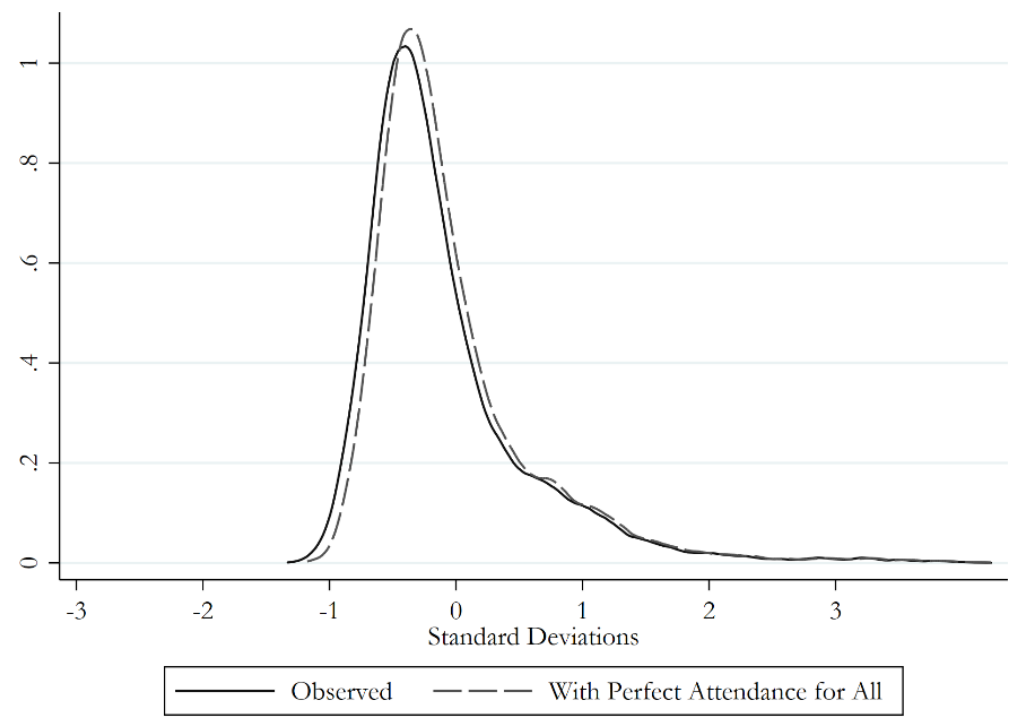




\section{Panel C. ECLS-K:2011 Cohort Math Test Score Distribution}

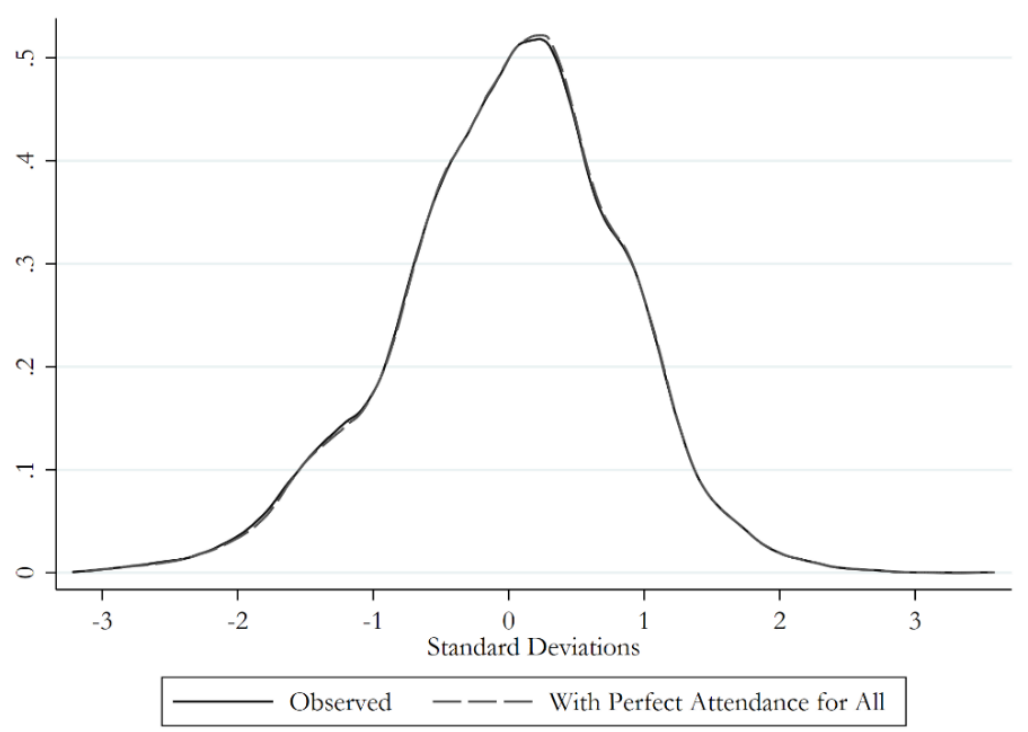

Panel D. ECLS-K:1998 Cohort Math Test Score Distribution

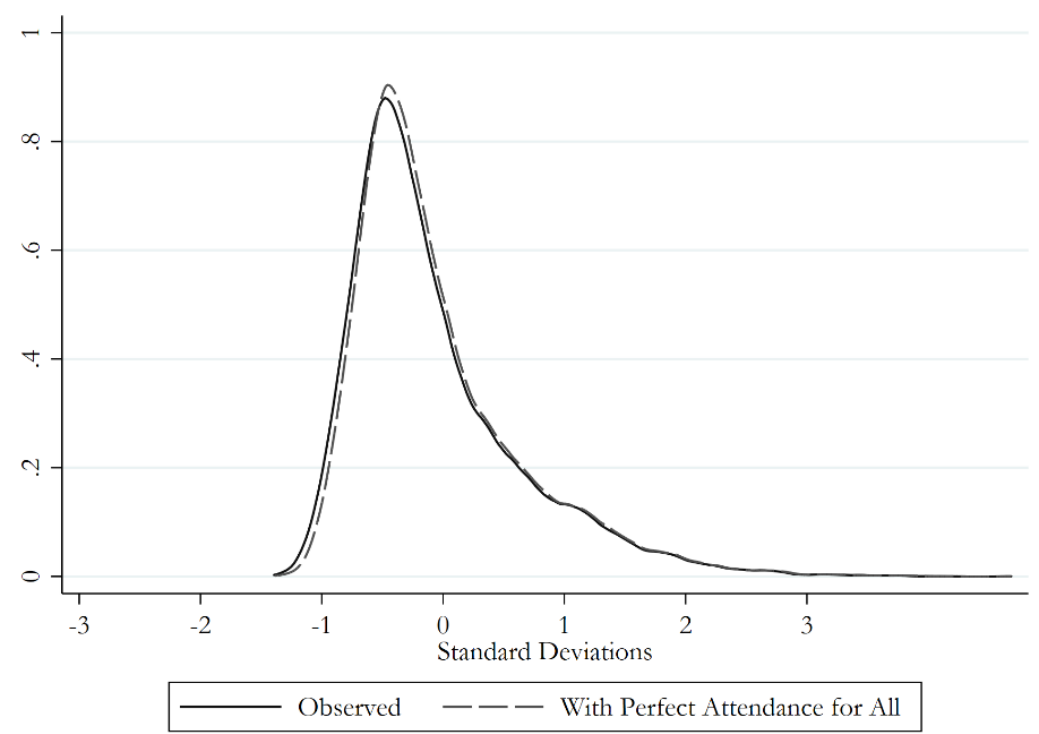

Sources: ECLS-K:1998 (N=18,456) and ECLS-K:2011 (N=17,143).

Note: Each sample includes kindergarten children with full information on spring reading and math cognitive assessments. The dependent variable is standardized math theta score from the spring cognitive assessment. Absences are teacherreported absences for each child for the school year. Models account for missing data using multiple imputation by chained equations over five imputed data sets, with ECLS-K survey weights applied. 
Appendix 
Table A1. Annual Kindergarten Absences and Reading Test Score Achievement

\begin{tabular}{|c|c|c|c|c|}
\hline \multirow[b]{3}{*}{ Independent Variable } & \multicolumn{4}{|c|}{ Cohort of Kindergartners } \\
\hline & \multicolumn{2}{|c|}{ ECLS-K:1998 } & \multicolumn{2}{|c|}{ ECLS-K:2011 } \\
\hline & $(1)$ & $(2)$ & (3) & $(4)$ \\
\hline \multicolumn{5}{|c|}{ Number of Absences (ref $=$ Zero) } \\
\hline \multirow[t]{2}{*}{ One to four } & -0.07 & -0.02 & 0.02 & 0.06 \\
\hline & $(0.04)$ & $(0.03)$ & $(0.06)$ & $(0.04)$ \\
\hline \multirow[t]{2}{*}{ Five to seven } & $-0.09 *$ & -0.04 & -0.05 & 0.05 \\
\hline & $(0.04)$ & $(0.03)$ & $(0.06)$ & $(0.04)$ \\
\hline \multirow[t]{2}{*}{ Eight to ten } & $-0.16^{* * *}$ & $-0.07 *$ & $-0.13^{*}$ & 0.06 \\
\hline & $(0.04)$ & $(0.03)$ & $(0.06)$ & $(0.04)$ \\
\hline \multirow[t]{2}{*}{ Eleven to nineteen } & $-0.24 * * *$ & $-0.09 *$ & $-0.24 * * *$ & 0.06 \\
\hline & $(0.04)$ & $(0.04)$ & $(0.06)$ & $(0.05)$ \\
\hline \multirow[t]{2}{*}{ Twenty or more } & $-0.46^{* * *}$ & $-0.16^{* * *}$ & $-0.56 * * *$ & -0.12 \\
\hline & $(0.04)$ & $(0.04)$ & $(0.09)$ & $(0.06)$ \\
\hline \multirow[t]{2}{*}{ Prior fall test score } & -- & 0.77 & -- & $0.66^{* * *}$ \\
\hline & & $(0.01)$ & & $(0.01)$ \\
\hline \multirow[t]{2}{*}{ Intercept } & 0.04 & -0.89 & 0.10 & -0.31 \\
\hline & $(0.04)$ & $(0.20)$ & $(0.05)$ & $(0.26)$ \\
\hline
\end{tabular}

Sources: ECLS-K:1998 (N=18,456) and ECLS-K:2011 ( $\mathrm{N}=17,143)$.

Note: Each sample includes kindergarten children with full information on spring reading and math cognitive assessments. The dependent variable is standardized reading theta score from the spring cognitive assessment. Absences are teacher-reported absences for each child for the school year. Models 2 and 4 also account for fall test score achievement and a range of demographic, family, and healthrelated characteristics of children at kindergarten entry. Models account for missing data using multiple imputation by chained equations over five imputed data sets, with ECLS-K survey weights applied. 
Table A2. Annual Kindergarten Absences and Math Test Score Achievement

\begin{tabular}{|c|c|c|c|c|}
\hline \multirow[b]{3}{*}{ Independent Variable } & \multicolumn{4}{|c|}{ Cohort of Kindergartners } \\
\hline & \multicolumn{2}{|c|}{ ECLS-K:1998 } & \multicolumn{2}{|c|}{ ECLS-K:2011 } \\
\hline & $(1)$ & $(2)$ & $(3)$ & $(4)$ \\
\hline \multicolumn{5}{|c|}{ Number of Absences (ref = Zero) } \\
\hline \multirow[t]{2}{*}{ One to four } & -0.05 & -0.01 & -0.02 & 0.02 \\
\hline & $(0.04)$ & $(0.04)$ & $(0.05)$ & $(0.03)$ \\
\hline \multirow[t]{2}{*}{ Five to seven } & -0.07 & 0.00 & -0.13 & -0.02 \\
\hline & $(0.05)$ & $(0.05)$ & $(0.05)$ & $(0.03)$ \\
\hline \multirow[t]{2}{*}{ Eight to ten } & $-0.18^{* *}$ & -0.05 & $-0.24 * * *$ & -0.01 \\
\hline & $(0.06)$ & $(0.05)$ & $(0.06)$ & $(0.04)$ \\
\hline \multirow[t]{2}{*}{ Eleven to nineteen } & $-0.26 * * *$ & -0.04 & $-0.39 * * *$ & -0.05 \\
\hline & $(0.05)$ & $(0.04)$ & $(0.06)$ & $(0.03)$ \\
\hline \multirow[t]{2}{*}{ Twenty or more } & $-0.51 * * *$ & $-0.12^{*}$ & $-0.67 * * *$ & $-0.15^{* *}$ \\
\hline & $(0.05)$ & $(0.05)$ & $(0.08)$ & $(0.05)$ \\
\hline \multirow[t]{2}{*}{ Prior fall test score } & -- & $0.69 * * *$ & -- & $0.74 * * *$ \\
\hline & & $(0.01)$ & & $(0.01)$ \\
\hline \multirow[t]{2}{*}{ Intercept } & 0.07 & $-1.54 * * *$ & 0.16 & $-0.91 * * *$ \\
\hline & $(0.05)$ & $(0.20)$ & $(0.05)$ & $(0.18)$ \\
\hline
\end{tabular}

Sources: ECLS-K:1998 (N=18,456) and ECLS-K:2011 ( $\mathrm{N}=17,143)$.

Note: Each sample includes kindergarten children with full information on spring reading and math cognitive assessments. The dependent variable is standardized reading theta score from the spring cognitive assessment. Absences are teacher-reported absences for each child for the school year. Models 2 and 4 also account for fall test score achievement and a range of demographic, family, and healthrelated characteristics of children at kindergarten entry. Models account for missing data using multiple imputation by chained equations over five imputed data sets, with ECLS-K survey weights applied 